\title{
Antimycin $\mathrm{A}_{18}$ produced by an endophytic Streptomyces albidoflavus isolated from a mangrove plant
}

\author{
Lei-Lei Yan ${ }^{1,2,8}$, Ning-Ning Han ${ }^{1,8}$, Yu-Qin Zhang ${ }^{1}$, Li-Yan Yu ${ }^{1}$, Jie Chen ${ }^{1}$, Yu-Zhen Wei ${ }^{1}$, Qiu-Ping Li ${ }^{1}$, \\ Ling Tao ${ }^{1}$, Guang-Hui Zheng ${ }^{1}$, Su-E Yang ${ }^{3}$, Cui-Xia Jiang ${ }^{3}$, Xin-De Zhang ${ }^{4}$, Qi Huang ${ }^{4}$, Xugela Habdin ${ }^{1,5}$, \\ Qiong-Bo $\mathrm{Hu}^{6}$, Zhou Li ${ }^{1}$, Shao-Wei Liu ${ }^{1}$, Zhi-Zhen Zhang ${ }^{7}$, Qi-Yang $\mathrm{He}^{1}$, Shu-Yi Si ${ }^{1}$ and Cheng-Hang Sun ${ }^{1}$
}

The Journal of Antibiotics (2010) 63, 259-261; doi:10.1038/ja.2010.21; published online 19 March 2010

Keywords: antimycin; endophytic actinomycetes; fungicide; mangrove plant; Streptomyces albidoflavus

Mangroves have unique intertidal ecosystems of the tropics, which possess prolific biodiversity of actinomycetes. ${ }^{1}$ Recent discoveries ${ }^{2,3}$ of new species of microorganisms from the ecosystems encouraged us to explore the bioactive secondary metabolites from endophytic actinomycetes isolated from mangrove plants. As a result, the cultured broth of the strain I07A-01824, an endophytic Streptomyces albidoflavus, isolated from the leaf of Bruguiera gymnorrhiza collected at Shankou, Guangxi Province, People's Republic of China, was found to show moderate inhibiting activity against Magnaporth grisea. By bioassayguided fractionation, antimycin $\mathrm{A}_{18}$ (1) was purified by chromatographies. By analyzing the spectroscopic data (including $1 \mathrm{D}$ and $2 \mathrm{D}$ NMR), its chemical structure was identified to be the first naturally occurring antimycin with an acetoxy group at C-8 (Figure 1).

The strain I07A-01824 identified as Streptomyces was isolated from the leaf of B. gymnorrhiza collected at Shankou, Guangxi Province, People's Republic of China. A stock culture of the strain I07A-01824 was maintained on yeast and malt extract with glucose (YMG) agar slant consisting of $0.4 \%$ yeast extract (Beijing Aoboxing Biotechnology, Beijing, China), $1 \%$ malt extract (Beijing Aoboxing Biotechnology), $0.4 \%$ glucose and $1.2 \%$ agar ( $\mathrm{pH}$ 7.2). The stock culture was inoculated into $250 \mathrm{ml}$ Erlenmeyer flasks containing $50 \mathrm{ml}$ of seed medium consisting of $0.5 \%$ glucose, $0.5 \%$ yeast extract, $0.5 \%$ peptone, $0.5 \%$ beef extract (Beijing Aoboxing Biotechnology), 0.4\% corn steep liquor (North China Pharmaceutical Corporation, Shijiazhuang City, China), $2 \%$ soluble starch, $1 \%$ soybean meal (Beijing Comwin Pharm-Culture, Beijing, China), $0.4 \% \mathrm{CaCO}_{3}$ and $0.002 \% \mathrm{CoCl}_{2}$ (pH 7.2). The flask culture was incubated on a rotary shaker ( 180 r.p.m.) at $28{ }^{\circ} \mathrm{C}$ for $36 \mathrm{~h}$. The seed culture $(50 \mathrm{ml})$ was transferred into each of 40 5-l Erlenmeyer flasks containing 11 of the same seed medium. The fermentation was carried out at $28^{\circ} \mathrm{C}$ for $72 \mathrm{~h}$ on a rotary shaker ( 180 r.p.m.).

The fermentation broth (401) was filtered and the filtrate was extracted with EtOAc (401). The extract was dried with $\mathrm{Na}_{2} \mathrm{SO}_{4}$, and then concentrated under reduced pressure to obtain syrup $(20 \mathrm{~g})$. It was then chromatographed on a column of silica gel (120 g, 100-200 mesh, Qingdao Ocean Chemical Group, Qingdao City, China, i.d. $3 \times 40 \mathrm{~cm})$ and developed with stepwise cyclohexane-EtOAc gradient system as below: 19:1 (v/v, $500 \mathrm{ml}), 4: 1(500 \mathrm{ml}), 2: 1(1000 \mathrm{ml})$ and 1:1 $(500 \mathrm{ml})$. The fraction of cyclohexane-EtOAc $(2: 1)$ showed the strongest fungicidal activity. This fraction $(1 \mathrm{~g})$ was further chromatographed on a column of RP-18 silica gel ( $40 \mathrm{~g}, 50 \mu \mathrm{m}$, Merck, Darmstadt, Germany, i.d. $1 \times 50 \mathrm{~cm}$ ) and eluted with $75 \%$ aqueous $\mathrm{MeOH}$ to yield a bioactive semipurified sample $(15 \mathrm{mg})$. This sample was dissolved completely in $1 \mathrm{ml} \mathrm{MeOH}$ and was purified by HPLC (detector: SPD-20AVP photodiode array detector (Shimadzu Corporation, Tokyo, Japan); column: YMC-Pack ODS-A (YMC Co. Ltd, Kyoto, Japan), $5 \mu$ m, i.d. $10 \times 250 \mathrm{~mm}$; mobile phase: $70 \%$ aqueous $\mathrm{MeOH}$; flow rate: $\left.2 \mathrm{ml} \mathrm{min}^{-1}\right)$ to yield $\mathbf{1}\left(6 \mathrm{mg}, R_{\mathrm{t}} 29 \mathrm{~min}\right)$.

Compound $\mathbf{1}$ was obtained as colorless amorphous solid and is soluble in $\mathrm{MeOH}$, dimethyl sulfoxide, EtOAc and $\mathrm{CHCl}_{3}$, but insoluble in $\mathrm{H}_{2} \mathrm{O}$ and $n$-hexane. The other physicochemical properties of 1 are as follows: HR-ESI-MS $(\mathrm{M}-1)^{-} \mathrm{m} / z$ 477.1872, calcd 477.1878 for $\mathrm{C}_{23} \mathrm{H}_{29} \mathrm{~N}_{2} \mathrm{O}_{9} ;[\alpha]_{\mathrm{D}}^{25}+49^{\circ}$ (c $\left.0.102, \mathrm{MeOH}\right) ; \lambda_{\max }^{\mathrm{MeOH}} \mathrm{nm}(\varepsilon) 227$

\footnotetext{
${ }^{1}$ Department of Microbial Chemistry, Institute of Medicinal Biotechnology, Chinese Academy of Medical Sciences \& Peking Union Medical College, Beijing, PR China; ${ }^{2}$ Department of Biotechnology, College of Life Science, Hebei University, Baoding, PR China; ${ }^{3}$ School of Pharmacy, Guilin Medical University, Guilin, PR China; ${ }^{4}$ Guangxi Shankou Mangrove Forest Protectorate, Beihai, PR China; ${ }^{5}$ Department of Microbiology, College of Biology, Xinjiang Normal University, Urimqi, PR China; ${ }^{6}$ Department of Pesticide Sciences, College of Natural Resources and Environment, South China Agricultural University, Guangzhou, PR China and ${ }^{7}$ Department of Biochemistry, Guangdong Medical College, Zhanjiang, PR China

${ }^{8}$ These authors contributed equally to this work.

Correspondence: Professor C Sun, Institute of Medicinal Biotechnology, Chinese Academy of Medical Sciences \& Peking Union Medical College, Tian Tan Xi Li No.1, Beijing 100050, PR China.

E-mail: chenghangsun@hotmail.com
}

Received 9 November 2009; revised 9 February 2010; accepted 23 February 2010; published online 19 March 2010 


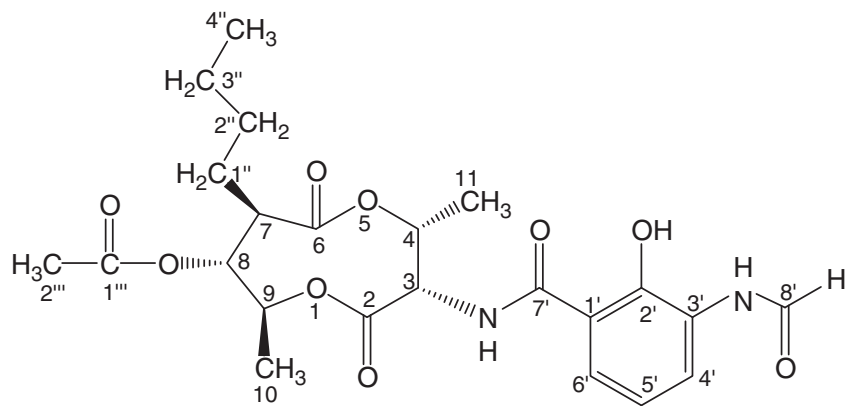

Figure 1 Structure of antimycin $\mathrm{A}_{18}$ (1).

Table 1 NMR data of antimycin $\mathrm{A}_{18}(1)$ in $\mathrm{CDCl}_{3}$

\begin{tabular}{|c|c|c|c|c|}
\hline Position & $\delta_{C}{ }^{a}$ & $\delta_{H}^{\mathrm{b}}($ mult, J (in Hz)) & ${ }^{1} \mathrm{H}_{-}{ }^{1} \mathrm{HCOSY}$ & $H M B C$ \\
\hline 2 & 170.1 & & & \\
\hline 3 & 53.7 & $5.29(\mathrm{dd}, 7.2,7.8 \mathrm{~Hz})$ & 7-NH, 3 & $2,4,11$ \\
\hline 4 & 71.0 & $5.73(\mathrm{dq}, 6.6,7.8 \mathrm{~Hz})$ & 3,11 & $2,6,11$ \\
\hline 6 & 172.9 & & & \\
\hline 7 & 50.1 & $2.51(\mathrm{dt}, 2.7,10.2,11.4 \mathrm{~Hz})$ & $1^{\prime \prime}, 8$ & $6,8,9$ \\
\hline 8 & 75.7 & $5.07(\mathrm{dd}, 9.6,10.2 \mathrm{~Hz})$ & 7,9 & $1^{\prime \prime \prime}, 7,9,10$ \\
\hline 9 & 74.8 & $4.98(\mathrm{dq}, 6.6,9.6 \mathrm{~Hz})$ & 8,10 & 2,8 \\
\hline 10 & 17.8 & $1.30(\mathrm{~d}, 6.6 \mathrm{~Hz})$ & 9 & \\
\hline 11 & 15.0 & $1.32(\mathrm{~d}, 6.6 \mathrm{~Hz})$ & 4 & 3 \\
\hline $1^{\prime}$ & 112.5 & & & \\
\hline $2^{\prime}$ & 150.6 & & & \\
\hline $2^{\prime}-\mathrm{OH}$ & & $12.62(\mathrm{~s})$ & & \\
\hline $3^{\prime}$ & 127.4 & & & \\
\hline $4^{\prime}$ & 124.8 & $8.55(\mathrm{~d}, 7.8 \mathrm{~Hz})$ & $5^{\prime}$ & $2^{\prime}, 6^{\prime}$, \\
\hline $5^{\prime}$ & 119.0 & $6.92(\mathrm{dd}, 7.8,7.2 \mathrm{~Hz})$ & $4^{\prime}, 6^{\prime}$ & $1^{\prime}, 3^{\prime}$ \\
\hline $6^{\prime}$ & 120.1 & $7.24(\mathrm{~d}, 7.2 \mathrm{~Hz})$ & $5^{\prime}$ & $2^{\prime}, 4^{\prime}, 7^{\prime}$ \\
\hline $7^{\prime}$ & 169.4 & & & \\
\hline $7^{\prime}-\mathrm{NH}$ & & $7.07(\mathrm{~d}, 7.2 \mathrm{~Hz})$ & 3 & $7^{\prime}$ \\
\hline $8^{\prime}$ & 159.0 & $8.51(\mathrm{~s})$ & & $3^{\prime}$ \\
\hline $8^{\prime}-\mathrm{NH}$ & & $7.93(\mathrm{br}, \mathrm{s})$ & & $4^{\prime}, 8^{\prime}$ \\
\hline $1^{\prime \prime}$ & 28.2 & $1.35(\mathrm{~m}), 1.70(\mathrm{~m})$ & $2 ", 7$ & $3^{\prime \prime}, 6$ \\
\hline $2^{\prime \prime}$ & 29.2 & $1.15(\mathrm{~m})$ & $1^{\prime \prime}, 3^{\prime \prime}$ & $4 "$ \\
\hline $3 "$ & 22.4 & $1.25(\mathrm{~m})$ & $2^{\prime \prime}, 4^{\prime \prime \prime}$ & $1^{\prime \prime}$ \\
\hline $4^{\prime \prime}$ & 13.8 & $0.88(\mathrm{t}, 6.6 \mathrm{~Hz})$ & $3^{\prime \prime}$ & $2^{\prime \prime}, 3^{\prime \prime}$ \\
\hline $1^{\prime \prime \prime}$ & 169.6 & & & \\
\hline $2^{\prime \prime \prime}$ & 20.8 & $2.13(\mathrm{~s})$ & & $1^{\prime \prime \prime}$ \\
\hline
\end{tabular}

a ${ }^{13} \mathrm{C}-\mathrm{NMR}$ was measured at $150 \mathrm{MHz}$.

(18.230), 319 (3.093); IR $v_{\max }(\mathrm{KBr}) \mathrm{cm}^{-1} 3348,2929,1738,1692$, $1635,1544,1373,1234,1202,1040,754$. The direct connectivity between protons and carbons was established by the heteronuclear single quantum coherence. The ${ }^{1} \mathrm{H}-\mathrm{NMR}$ and ${ }^{13} \mathrm{C}-\mathrm{NMR}$ spectral data of $\mathbf{1}$ are shown in Table 1.

Five carbonyl carbon signals $(\delta 172.9,170.1,169.6,169.4$ and 159) and six olefinic carbon signals $(\delta 150.6,127.4,124.8,120.1,112.5$ and 119) were readily observed by analysis of ${ }^{13} \mathrm{C}-\mathrm{NMR}$ and DEPT of 1. Further analysis of the six olefinic carbon signals through heteronuclear single quantum coherence together with ${ }^{1} \mathrm{H}-{ }^{1} \mathrm{H}$ COSY and HMBC (Figure 2) revealed that the three quaternary carbon signals at $\delta 112.5\left(\mathrm{C}-1^{\prime}\right), \delta 150.6\left(\mathrm{C}-2^{\prime}\right)$ and $\delta 127.4\left(\mathrm{C}-3^{\prime}\right)$, and three tertiary carbon signals at $\delta 124.8\left(\mathrm{C}-4^{\prime}\right), \delta 119\left(\mathrm{C}-5^{\prime}\right)$ and $\delta 120.1\left(\mathrm{C}-6^{\prime}\right)$ formed a $1,2,3$-trisubstituted benzene ring, as proton signal at $\delta 6.92$

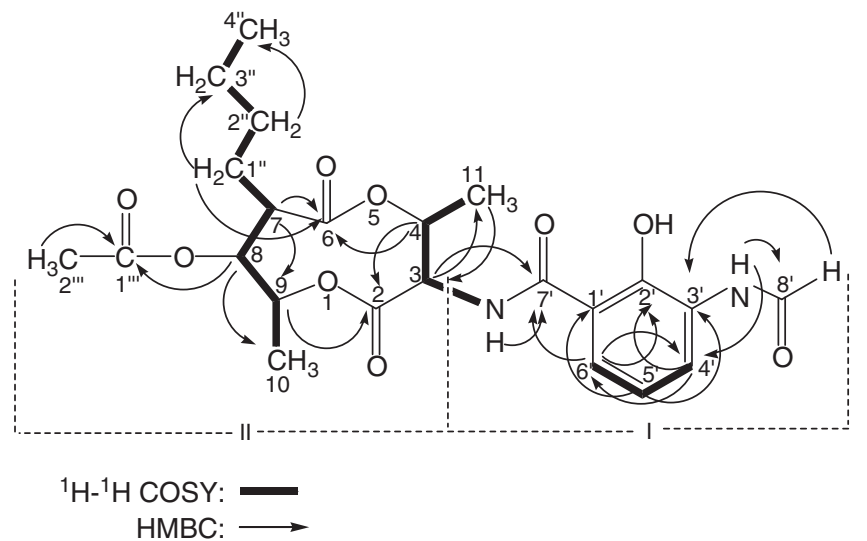

Figure 2 Summary of ${ }^{1} \mathrm{H}_{-}{ }^{1} \mathrm{H}$ COSY and selected $\mathrm{HMBC}$ correlations of $\mathbf{1}$.

$\left(1 \mathrm{H}, \mathrm{dd}, J=7.8,7.2 \mathrm{~Hz}, 5^{\prime}-\mathrm{H}\right)$ was coupled with proton signals at $\delta 8.55\left(1 \mathrm{H}, \mathrm{d}, J=7.8 \mathrm{~Hz}, 4^{\prime}-\mathrm{H}\right)$ and $\delta 7.24\left(1 \mathrm{H}, \mathrm{d}, J=7.2 \mathrm{~Hz}, 6^{\prime}-\mathrm{H}\right)$ in ${ }^{1} \mathrm{H}-{ }^{1} \mathrm{H}$ COSY. Both $4^{\prime}-\mathrm{H}$ and $6^{\prime}-\mathrm{H}$ were long-range correlated with $\mathrm{C}-2^{\prime}$, and $5^{\prime}-\mathrm{H}$ was long-range correlated with $\mathrm{C}-1^{\prime}$ and $\mathrm{C}-3^{\prime}$ in HMBC.

The proton signals at $\delta 12.62,8.51,7.93$ and 7.07 were also readily observed and assigned to a phenolic hydroxyl proton $\left(2^{\prime}-\mathrm{OH}\right)$, formyl proton $\left(8^{\prime}-\mathrm{H}\right)$ and two amide protons $\left(3^{\prime}-\mathrm{NH}\right.$ and $\left.7^{\prime}-\mathrm{NH}\right)$, respectively. According to the chemical shift of $150.6\left(\mathrm{C}-2^{\prime}\right)$, a phenolic hydroxyl was substituted at $\mathrm{C}-2^{\prime}$. By tracing cross peaks from the two amide protons $\left(3^{\prime}-\mathrm{NH}\right.$ and $\left.7^{\prime}-\mathrm{NH}\right)$ in HMBC, two amide carbonyl carbons of $\delta 159\left(\mathrm{C}-8^{\prime}\right)$ and $\delta 169.4\left(\mathrm{C}-7^{\prime}\right)$ were assigned. The cross peaks observed in HMBC between $6^{\prime}-\mathrm{H}$ and $\mathrm{C}-7^{\prime}, 8^{\prime}-\mathrm{H}$ and $\mathrm{C}-3^{\prime}$, as well as $3^{\prime}-\mathrm{NH}$ and $\mathrm{C}-4^{\prime}$, indicated that the side chains of $-\mathrm{NHCO}^{-}$and $-\mathrm{NHCHO}$ were linked to the benzene ring at $\mathrm{C}-1^{\prime}$ and $\mathrm{C}-3^{\prime}$, respectively. It led to the unambiguous assignments of NMR data in the substructure I (Figure 2).

As the five carbonyl carbons and one benzene ring in $\mathbf{1}$ accounted for nine of the ten degrees of unstauration required for the molecular formula, 1 should have another ring. This was confirmed by tracing cross peaks in the ${ }^{1} \mathrm{H}_{-}{ }^{1} \mathrm{H}$ COSY and HMBC from the three oxymethine protons at $\delta 5.73(1 \mathrm{H}, \mathrm{dq}, J=6.6,7.8 \mathrm{~Hz}, 4-\mathrm{H}), \delta 5.07(1 \mathrm{H}$, $\mathrm{dd}, J=9.6,10.2 \mathrm{~Hz}, 8-\mathrm{H})$ and $\delta 4.98(1 \mathrm{H}, \mathrm{dq}, J=6.6,9.6 \mathrm{~Hz}, 9-\mathrm{H})$ observed in ${ }^{1} \mathrm{H}-\mathrm{NMR}$. The cross peaks in ${ }^{1} \mathrm{H}-{ }^{1} \mathrm{H}$ COSY between the proton at $\delta 5.29(1 \mathrm{H}, \mathrm{dd}, J=7.2,7.8 \mathrm{~Hz}, 3-\mathrm{H})$ and $4-\mathrm{H}$, the proton at $\delta$ $2.51(1 \mathrm{H}, \mathrm{dt}, J=2.7,10.2,11.4 \mathrm{~Hz}, 7-\mathrm{H})$ and $8-\mathrm{H}, 8-\mathrm{H}$ and $9-\mathrm{H}$, together with the cross peaks in $\mathrm{HMBC}$ between $4-\mathrm{H}$ and $\mathrm{C}-2(\delta$ $170.1), 4-\mathrm{H}$ and C-6 ( $\delta$ 172.9), 9-H and C-2, 7-H and C-9 ( $\delta$ 74.8), 7$\mathrm{H}$ and $\mathrm{C}-6$ established the structure of the nine-membered dilactone ring in 1 . The two methyl proton signals at $\delta 1.30(3 \mathrm{H}, \mathrm{d}, J=6.6 \mathrm{~Hz}$, $\left.10-\mathrm{CH}_{3}\right)$ and $\delta 1.32\left(3 \mathrm{H}, \mathrm{d}, J=6.6 \mathrm{~Hz}, 11-\mathrm{CH}_{3}\right)$ observed in ${ }^{1} \mathrm{H}-\mathrm{NMR}$ were assigned by ${ }^{1} \mathrm{H}-{ }^{1} \mathrm{H}$ COSY, and long-range coupling between $3-\mathrm{H}$ and $\mathrm{C}-11(\delta 15), 11-\mathrm{H}$ and $\mathrm{C}-3(\delta 53.7), 8-\mathrm{H}$ and $\mathrm{C}-10(\delta 17.8)$ in HMBC further confirmed their substitute position in the ring. A butyl side chain linked with the ring at C-7 was identified by the contiguous correlation from $1^{\prime \prime}-\mathrm{H}$ to $4^{\prime \prime}-\mathrm{H}$ in ${ }^{1} \mathrm{H}-{ }^{1} \mathrm{H}$ COSY and correlations from proton signals at $\delta 1.35,1.70\left(2 \mathrm{H}, \mathrm{m}, \mathrm{1}^{\prime \prime}-\mathrm{H}\right)$ to $\mathrm{C}-6$ and $\mathrm{C}-3^{\prime \prime}(\delta 22.4)$ in HMBC. The final acetoxy group at the C- 8 was revealed by the cross peaks between $8-\mathrm{H}$ and $\mathrm{C}-1^{\prime \prime \prime}(\delta$ 169.6) and between proton signal at $\delta$ $2.13\left(3 \mathrm{H}, \mathrm{s}, 2^{\prime \prime \prime}-\mathrm{H}\right)$ and $\mathrm{C}-1^{\prime \prime \prime}$ in HMBC. These results indicated the presence of substructure II in $\mathbf{1}$ (Figure 2).

Linkage between the two substructures (I and II) was established by ${ }^{1} \mathrm{H}_{-}{ }^{1} \mathrm{H}$ COSY and HMBC. The proton signal at $\delta 5.29(1 \mathrm{H}, \mathrm{dd}$, $J=7.2,7.8 \mathrm{~Hz}, 3-\mathrm{H})$ was coupled with the proton signal at $\delta 7.07$ 
$\left(1 \mathrm{H}, \mathrm{d}, J=7.2 \mathrm{~Hz}, 7^{\prime}-\mathrm{NH}\right)$ in ${ }^{1} \mathrm{H}-{ }^{1} \mathrm{H}$ COSY, meanwhile, the long-range coupling between $3-\mathrm{H}$ and $\mathrm{C}-7^{\prime}(\delta$ 169.4) was observed in HMBC. The data above revealed the linkage of the two substructures through $7^{\prime}$-NH with 3-CH. Thus, the planar structure of 1 was determined.

Hosotani et al. ${ }^{4}$ has reported the stereochemistry of antimycin $\mathrm{A}_{13}$ and Hayashi and Nozaki ${ }^{5}$ established the same configuration of the nine-membered dilactones of kitamycins A and B and urauchimycin B with that of antimycin $\mathrm{A}_{13}$ by analyzing NOESY. Compound 1 possessed the same configuration of the nine-membered dilactones (Figure 1) with antimycin $A_{13}$ because of the strong agreement between the NMR data of the nine-membered dilactones of 1 and that of the antimycin $\mathrm{A}_{13}$; in addition, the optical rotation of 1 in $\mathrm{MeOH}$ is very similar to the urauchimycin $\mathrm{B}$ in $\mathrm{MeOH} .{ }^{6}$ The NOE experiment of 1 further confirmed the result. Irradiation of the proton signal at $3-\mathrm{H}(\delta 5.29)$ resulted in an NOE enhancement $(+5.58 \%)$ in the proton signal at $4-\mathrm{H}(\delta 5.73)$; in turn, the irradiation of the $4-\mathrm{H}$ resulted in the enhancement $(+8.08 \%)$ of the $3-\mathrm{H}$. Irradiation of the proton signal at the $7-\mathrm{H}(\delta 2.51)$ showed no enhancement of the $8-\mathrm{H}$ $(\delta 5.07)$, but an enhancement $(+4 \%)$ of the $9-\mathrm{H}(\delta 4.98)$.

As of now, different substituent of the alkyl side chains at C-7 and the oxygen substituent at C-8 in the nine-membered dilactone ring have generated about 30 naturally occurred antibiotics of the antimycin group. ${ }^{7}$ Except antimycin $\mathrm{A}_{9}$ that has an 8-phenylacetyl residue, ${ }^{8}$ all the compounds in the antimycin A series from antimycin $A_{1}$ to $A_{17}$ possess a $C_{4}$ to $C_{7}$ aliphatic acyl side chain at C-8. ${ }^{4,9}$ Thus, 1 was the first naturally occurring antimycin that has an 8-O-acetyl side chain, and we named it antimycin $\mathrm{A}_{18}$.

Hockenbery et al. ${ }^{10}$ has synthesized a series of 2-methoxy antimycin derivatives, including $\mathbf{1}$, as bioactive inhibitors for the Bcl-2 family members in an attempt to treat apoptosis-associated diseases. On the other hand, antimycins have the potential to be developed as fungicide. ${ }^{9}$ Acylation of the 8-hydroxy group of antimycins has shown close relationship with their antifungal activities. ${ }^{7}$ Owing to the free hydroxyl group at C-8, kitamycins A and B, as well as urauchimycins $\mathrm{A}$ and $\mathrm{B}$, showed weak antifungal activities only. ${ }^{7}$ Hosotani et al. ${ }^{4}$ have reported that there are inverse relationships between the antifungal activity and the length of the 7-alkyl and 8-O-acyl side chains of antimycins. Using four strains of plant pathogenic fungi: Colletotrichum lindemuthianum, Botrytis cinerea, Alternaria solani and M. grisea as test strains, $\mathbf{1}$ and positive control, blasticidin S (Invitrogen, Carlsbad, CA, USA) were tested in serials dilution assay on a paper
( $6 \mathrm{~mm}$ i.d.) disk with potato dextrose agar medium. The minimum concentration values of $\mathbf{1}$ to show inhibition zone on plates were 0.01 , $0.06,0.03$ and $0.20 \mu \mathrm{g} \mathrm{ml}^{-1}$, respectively, whereas those of blasticidin S were $0.20,0.60,0.12$ and $0.01 \mu \mathrm{g} \mathrm{ml}^{-1}$, respectively. Except M. grisea, the respective minimum concentration values of 1 against C. lindemuthianum, B. cinerea and A. solani were 20, 10 and 4 times less than those of blasticidin $S$, a commercialized fungicide. It indicated that 1 , as a member of antimycins with the shortest $O$ alkylacyl side chain at C-8, has a potential to be developed for plant protection in the field.

\section{ACKNOWLEDGEMENTS}

This work was supported by the Key New Drug Creation and Manufacturing Programme (Grant No. 2009ZX09301-003, Grant No. 2009ZX09303-004) and the National Facilities and Information Infrastructure for Science and Technology (Grant No. 2005DKA21203) funded by the Ministry of Science and Technology of the People's Republic of China, and the National Natural Science Foundation of China (NSFC; Grant No. 30970008).

1 Hong, K. et al. Actinomycetes for marine drug discovery isolated from mangrove soils and plants in China. Mar. Drugs 7, 24-44 (2009).

2 Thawai, C., Tanasupawat, S. \& Kudo, T. Micromonospora pattaloongensis sp. nov., isolated from a Thai mangrove forest. Int. J. Syst. Evol. Microbiol. 58, 1516-1521 (2008).

3 Ara, I., Kudo, T., Matsumoto, A., Takahashi, Y. Ōmura, S. Nonomuraea maheshkhaliensis sp. nov., a novel actinomycete isolated from mangrove rhizosphere mud. J. Gen. Appl. Microbiol. 53, 159-166 (2007).

4 Hosotani, N., Kumagai, K., Nakagawa, H., Shimatani, T. \& Saji, I. Antimycins $A_{10} \sim A_{16}$, seven new antimycin antibiotics produced by Streptomyces spp. SPA-10191 and SPA-8893. J. Antibiot. 58, 460-467 (2005).

5 Hayashi, K. I. \& Nozaki, H. Kitamycins, new antimycin antibiotics produced by Streptomyces sp. J. Antibiot. 52, 325-328 (1999).

6 Immamura, N., Nishijima, M., Adachi, K. \& Sano, H. Novel antimycin antibiotics, urauchimycins A and B, produced by marine actinomycete. J. Antibiot. 46, 241-246 (1993).

7 Yao, C. B. F., Schiebel, M., Helmke, E, Anke, H. \& Laatsch, H. Prefluostatin and new urauchimycin derivatives produced by Streptomycete isolates. Z. Naturforsch. B. 61, 320-325 (2006).

8 Shiomi, K. et al. A new antibiotic, antimycin A9, produced by Streptomyces sp. K010031. J. Antibiot. 58, 74-78 (2005).

9 Chen, G. Y. et al. A new fungicide produced by a Streptomyces sp. GAAS7310. J. Antibiot. 58, 519-522 (2005).

10 Hockenbery, D. M., Simon, J. A., Tzung, S. P. \& (Fred Hutchinson Cancer Research Center) 2-Methoxy antimycin A derivatives and methods of use. U.S. 2005/ 02398731A1, 27 October 2005. 